\title{
Post dated Pregnancy and its Maternal and Fetal Outcome.
}

\author{
Kana R Odedara* , Pooja A Kamaria** \\ *Resident. Obstetrics and Gynecology department, Shri M. P. Shah Government Medical College and GGG \\ Hospital, Jamnagar, Gujarat. \\ **Resident. Microbiology department, Shri M. P. Shah Government Medical College and GGG Hospital, \\ Jamnagar, Gujarat.
}

\section{Introduction}

Post term pregnancy is associated with an increased risk of fetal and neonatal mortality and morbidity as well as an increased maternal morbidity [1,2]. Exact etiology is not known but some risk factors are associated with postterm pregnancy like parity, maternal age , past history of postterm pregnancy, genetics and obesity $[3,4]$

Although the last menstrual period (LMP) has been traditionally used to calculate the estimated due date (EDD), many inaccuracies exist using this method in women who have irregular cycles, have been on recent hormonal birth control, or who have first trimester bleeding. In particular, women are more likely to be oligo-ovulatory than polyovulatory, so cycles longer than 28 days are not uncommonly seen [5].

Postterm pregnancy associated with an increased risk of postnatal mortality and morbidity including meconium aspiratiom syndrom, oligohydramnios, macrosomia, fetalbirth injuries, septisemia, rate of non reassuring fetal heart rate, fetal distress in labour and maternal complication incresed c.s rate, cephalopelvic disproportion, cervical tear, dystocia, post partamhemorrhage [6].

Management protocol for postterm pregnancy is fetal surveillance for prolonged pregnancy, induction of labour, during intrapartum care proper monitoring of labour [7].

\section{Material And Methods}

This study was carried out in the Department of Obstetrics and Gynecology, Shri M. P. Shah Government Medical College, Jamnagar, Gujarat from March 2015 to November 2015. A total of 100 patients beyond 40 weeks of gestation admitted in Obstetrics and Gynecology Department, GG Hospital, Jamnagar have been taken in the study group. Inclusion criteria are -1 . Antenatal cases beyond 40 weeks of gestation aged between 18yrs and 35 yrs. 2. With regular menstrual cycles and known LMP or with first trimester scan. 3 . Singleton pregnancy with vertex presentation. Exclusion criteria are - 1.Congenital anomalies 2.Chronic hypertension, pre eclampsia and eclampsia 3. Pre-existing or gestational diabetes 4. Heart diseases 5. Antepartum haemorrhage.

The data are collected using a prepared proforma meeting the objectives of the study by means of personal interview with the patients after taking informed consent. The data are collected from the pregnant females between 18yrs and $35 \mathrm{yrs}$ of age as per the inclusion and exclusion criterias. Using week of gestation as the primary predictor variable, its association with the following outcomes had been examined-in our study we have select 100 cases by lottery method and out of them 24 deliverd spontaneously and 76 were induced. We have used cerviprime, intracervical foleys and misoprostole tab $25 \mathrm{mcg}$ for induction of labour.

Ethical clearance: it is a retrospective analysis of samples tested for routine laboratory diagnosis; hence ethical clearance is not necessary.

Statistics: Data was entered and analyzed in MS excel 2007.

\section{Results}

Table-1 shows distribution of patients according to maternal complications associated with postterm pregnancies. In $87 \%$ of patients there were no complications and among the complications, PPH (6\%) was the most common complication in postterm pregnancy.

Table-2 shows distribution of patients according to fetal complications. Maconium Aspiration Syndrome (MAS) was the most common (45\%) complication in postterm pregnancy.

Table-3 shows distribution of patients according to outcome, it shows that LSCS (62\%) was the commonest among all.

Induction was done in 76 patients. Table-4 shows distribution of patients according to type of induction. 


\section{Discussion}

Present study shows that among maternal complications PPH was $6 \%$ and no complications in $87 \%$. A comparative study done by Dr Vijaykumar et al. [7] shows rate of PPH was $3.5 \%$ and no complications in $87.5 \%$.

A comparative study done by Farhat naz/amina javid et al. [8] shows for fetal complications, rate of MAS, Asphyxia and Jaundice was $68 \%, 55 \%$ and $8 \%$ respectively.

For distribution of patients according to pregnancy outcome a comparative study done by Farhat naz/amina javid et al. [8] shows that rate of LSCS, FTVD (spontaneous or induced) and Instrumentation was $70 \%, 18.33 \%$ and $11.67 \%$ respectively.

In the present study, induction of labour was done in $76 \%$ of postterm pregnancy. A comparative study done by C.J.M Sneijers et al. shows $88.7 \%$ rate of induction in postterm pregnancy.

Present study shows that percentage for type of induction for Cerviprime, Foleys and misoprostol $(25 \mu \mathrm{g})$ was $69.74 \%, 21.05 \%$ and $9.21 \%$, a comparative study done by Ss Ramesh et al. shows $74.4 \%, 17.7 \%$ and $9.21 \%$ for Cerviprime, Foleys and misoprostol $(25 \mu \mathrm{g})$ respectively.

\section{Conclusion}

We conclude Post term pregnancies require early detection, effective and proper planning management. The mere fact that the pregnancy is post term does not necessitate a hasty line of management towards operative delivery. Provided there are no contraindications for caesarean, post term pregnancy per se is not a contraindication for the same.

\section{References}

[1]. Olesen AW, Westergaard JG, Olsen J. Perinatal and maternal complications related to postterm delivery: A national register-based study, 1978-1993. Am J Obstet Gynecol. 2003;189:222-227.[PubMed]

[2]. Caughey AB, Stotland NE, Washington AE, et al. Maternal obstetric complications of pregnancy are associated with increasing gestational age at term. Am J Obstet Gynecol. 2007;196:155.e1-e6.[PMC free article] [PubMed]

[3]. Divon MY, Haglund B, Nisell H, Otterblad PO, Westgren M. Fetal and neonatal mortality in the postterm pregnancy: the impact of gestational age and fetal growth restriction. Am J Obstet Gynecol 1998;178 (4):726-31.

[4]. Van Eyk N, Allen LM, Sermer M, Davis VJ. Obstetric outcome of adolescent pregnancies. Journal of Pediatric and Adolescent Gynecology 2000;13 (2):96.

[5]. Savitz DA, Terry JW Jr, Dole N, et al. Comparison of pregnancy dating by last menstrual period, ultrasound scanning, and their combination. Am J Obstet Gynecol. 2002 Dec. 187(6):1660-6. [Medline].

[6]. Cunningham FG, Leveno KJ, Bloom SL, Hauth JC, Larry CG III, Wenstrom KD. Post-term pregnancy. 23 ${ }^{\text {rd }}$ ed. In: William's Obstetrics. New York: McGraw-Hill Companies; 2010. pp. 832-41.

[7]. Nanda Shinge, Vijay Kumar .M.M, Prashanth.S. "Comparative Study of Material \& Fetal Outcome in Pregnancies of Gestational Age 40 Completed Weeks and Beyond”. Journal of Evolution of Medical and Dental Sciences 2013; Vol2, Issue 25, June 24; Page: 4509-4515.

[8]. Farhat N, Amina J, Sara S, Altaf B, Amtullah Z. Neonatal Outcome in Post-term Pregnancy. PJMHSONLINE. 2009.

Table-1: Distribution of patients according to maternal complications

\begin{tabular}{|c|c|}
\hline Complications & Percentage (\%) \\
\hline PPH & 6 \\
\hline Cervical tear & 5 \\
\hline Perinatal tear & 1 \\
\hline Shoulder dystocia & 1 \\
\hline No complications & 87 \\
\hline
\end{tabular}

Table-2: Distribution of patients according to fetal complications

\begin{tabular}{|c|c|}
\hline Complications & Percentage (\%) \\
\hline MAS & 45 \\
\hline Asphyxia & 40 \\
\hline Jaundice & 4 \\
\hline
\end{tabular}

Table-3: Distribution of patients according to pregnancy outcome

\begin{tabular}{|c|c|}
\hline Pregnancy outcome & Percentage (\%) \\
\hline LSCS & 62 \\
\hline FTVD(spontaneous or induced) & 38 \\
\hline Instrumentation & 0 \\
\hline
\end{tabular}

Table-4: Distribution of the patient according to types of induction

\begin{tabular}{|l|c|c|}
\hline Tpes of induction & Total no. of patients $(\mathbf{n = 7 6})$ & Percentage $(\%)$ \\
\hline Cerviprime & 53 & $69.74 \%$ \\
\hline foleys & 16 & $21.05 \%$ \\
\hline Misoprostol(25mcg) & 07 & $9.21 \%$ \\
\hline
\end{tabular}

